\title{
New tendencies of sustainable development: providing personal security and quality of life as a new national security paradigm
}

\author{
Oleh Anatoliyovych Zubchyk ${ }^{1 *}$, Mykhailo Ivanovych Boichenko ${ }^{2}$ and Gryhoriy Petrovych \\ Sytnyk $^{3}$, Vasyl Vasyliovych Levkulych ${ }^{4}$ \\ ${ }^{1}$ Doctor of Science in Public Administration, Docent, Associate Professor of Taras Shevchenko \\ National University of Kyiv, Kyiv, Ukraine \\ ${ }^{2}$ Doctor of Science in Social Philosophy, Professor, Professor of Taras Shevchenko National \\ University of Kyiv, Kyiv, Ukraine. \\ ${ }^{3}$ Doctor of Science in Public Administration, Professor, Professor of Taras Shevchenko National \\ University of Kyiv, Kyiv, Ukraine. \\ ${ }^{4}$ Candidate of Philosophical Sciences, Associate Professor at the Department of Philosophy, \\ Uzhhorod National University, Uzhhorod, Ukraine.
}

\begin{abstract}
The article is devoted to the analysis of the theoretical foundations of public administration and administration in the field of public security and civil defense as a component of the national security system. Consideration of the problems of civilizational development and national security shows the urgent need to rethink the areas of responsibility of state and civil society, the ratio of hierarchical and network structures in public administration and management. There is also a need to implement a new principle of boosting standards of living, as a prerequisite to ensuring national security, through sustainable development of society and competitiveness of the state itself. It is shown that under the conditions of globalization the state is no longer ensuring security and well-being of its citizens by mere «defending» them from the threats of emergencies. The state must prepare citizens to be able to confront the various globalization-related challenges on their own. Earlier this year, the National Security and Defense Council of Ukraine submitted a draft national security strategy "Personal Security National Security" to the President for consideration. In this regard the new model of public administration and administration system in the field of public security and civil defense can be efficient. It is based on the six pillars of public administration. These are «human being / human resource», «organization theory», «policy analysis», «budgeting», «statistics» and «ethics». Such a framework ensures the unity of the system development approach in combination with theory and practice.
\end{abstract}

\section{Introduction}

Global sustainable development deals not only economic and social issues, but security issues as well. It is common security of mankind first of all. So the issues of national state security should be coordinate with UN global strategic plan entitled "Transforming Our World: A Sustainable Development Agenda for 2030" [1]. There are

\footnotetext{
*Corresponding author: ise-cupw@ukr.net
} 
several common responsibility area for the UN and national states and first of them is the area of personal security and defence of quality of life.

The tasks of combating national security threats in the field of civil defense in modern global security situation is closely related to the development of public security and civil protection on the local and global level as well. Improvement in carrying out these tasks is determined by the needs of adequate responces on the current challenges and threats in the field of national security and should be based on the idea of integrating forecasting tasks, preemptive actions to counter threats, emergency response and its recovery. Global sustainable development depends on achieving the goals of sustainable development in every regional system of public administration and management, on formation of national state competitiveness, and most importantly - ensuring a high quality of life and organically fit of every person as a citisen into the national security system.

Considerations mentioned above stipulate for a need to rethink the understanding of both the system of public administration and management in the field of public security and civil defense in the context of national security, as well as the goals of sustainable development in their regional dimension.

The Quality of Life (QoL) issues are profoundly studied within the framework of the World Health Organization (WHO) programs, which define the QoL as «an individual's perception of their position in life in the context of the culture and value systems in which they live and in relation to their goals, expectations, standards and concerns» [2] and the United Nations Organization, which generally takes QoL as a "Standard of Living", and the main indicator of QoL in this regard is the Human Development Index (HDI), developed by the UNDP staff (UNDP) [3]. It is based on the measurement of three parameters: life expectancy, education level and GDP (Gross domestic product) per capita. Besides, it should be mentioned that in 2009 the Commission on the Measurement of Economic Performance and Social Progress (CMEPSP), chaired by the Nobel Laureates Joseph Stiglitz (President of the Commission) and Amartya Sen (Advisor), published a report proposing to replace the economic component of evaluation (GDP) with an indicator of QoL, giving it the importance of the main criterion of economic development of society, which also included one more component - security. In 2017, the QoL indicators were adopted due to the CMEPSP report.

The aim of the study is to substantiate a provision, which stipulates for one of the national security mechanisms is the system of public administration and management in the field of public security and civil defense, which, according to our model, is based on "six pillars" of public administration and management, such as "individual", "organization theory", "policy analysis", "budgeting", "statistics", "ethics", which ensures the unity of such an approach as a system-forming one with a combination of theory and practice of security (such security climate, when an individual feels protected) - as citizens' quality of life.

\section{Research methodology}

The research methodology is a systematic approach, which is based on the principles of "versatility", "multidimensionality", "hierarchy", "diversity", "dynamism". These principles allow to consider the system of public administration and management in the field of public safety and civil defense as a system that has its own specific features, and which is a part of the national security system, and characterized by a large set of properties, organized in groups, each of them describing some peculiarities. In addition, the study of complex objects, one of which is represented by the system of public administration and management in the field of public safety and civil defense in terms of a systematic approach, which is based on the ideas of hierarchical structure and net structures. The hierarchical 
structure places the parts or elements of the whole in order from highest to lowest levels. Network structures complenment hierarchical ones and provide risoma-like horizontal pluralistic, flexible and changeable social relations in multitude of communities on each level. In these two ways the hierarchical pattern of the public administration and management system in the field of public safety and civil defense and its properties, respectively creates regularities of different order. The system approach also requires consideration of the public administration and management system in the field of public safety and civil defense in their development at all stages of this system "life cycle".

\section{Results of the research}

Public safety, as protection of vital interests of society and individuals, human and civil rights, protection from unlawful encroachments, emergencies that pose a threat to health and property of a significant number of people and civil defense, as the function of the state, which is aimed at protecting the population, territories, environment and property from emergencies by preventing such situations, eliminating their consequences and providing assistance to victims in peacetime and during special periods; they play a crucial role in all over the world in preparing for and responding to disasters, helping millions of people every year.

The national security system of Ukraine today includes a set of basic types of security, ensuring the need to implement tasks in the interests of society and the state.

However, in considering the problems of civilization development and ensuring national security, these issues are often considered separately, both in theoretical and applied aspects.

At the present stage of social development, the developed countries are implementing a new principle of national security in the whole range of its components - the principle of national security through sustainable development of society and the competitiveness of the state. Which entities provide this and what threats do they face? If the state is no longer a «sovereign territory», it becomes a «territory of competition», which results in rivalry, struggle, conflict and even war between different actors and groups for the sake of globalization as a benefit, and those who took the brunt of its inevitable negative consequences, than who among the other actors, such as - local self-government authorities, market participants or civil society actors can guarantee the achievement of such goals?

In the context of globalization, the state no longer provides its citizens with social welfare only by protecting it from the external pressures of competition. The state prepares its citizens for various globalization challenges. Those areas of activity and control, where the state has traditionally been considered the one and only in its efficiency, are now performed by other actors, not only market actors, but also civil society actors and some individuals in general.

We are talking about the resource utilization, various services, education and medicine, and even about security and defense. According to J. Rosenau [4], the international relations are now ruled by an individual acting as a «tourist» and «terrorist», what indicates an «erosion of state sovereignty». As for the internal affairs, the determining factor here is an individual as a citizen, who seeks to realize his civic potential.

These structural changes, which began in the last decade of the twentieth century and continue to this day. On the one hand, they solidified the interdependence of peoples and societies, but on the one hand, they also caused profound transformations, both in international relations and in domestic affairs of the countries. Transnationalization and growing threat of capital outflows are forcing the governments to launch market-oriented 
mechanisms and tools, thus limiting protectionism and regulativity, digitizing and shrinking from the size of the giant Leviathan [5] to the size of a pocket smartphone.

Hard factors, identified as imminent threats to the national security of Ukraine and recorded in the National Security Strategy of Ukraine. In the context of formal approach, security is often interpreted as the protection of interests (including national ones) from internal and external threats. In particular, the Law of Ukraine «On National Security» determines that public safety and order as «protection of vital interests of society and individual, human rights and freedoms, ensuring which is a priority for security forces, other state bodies, local authorities, their officials and the public, which take coordinated steps to realize and protect national interests from the impact of threats.

The system of public safety and civil defense provides an important function in ensuring the protection of residential areas and territories during peacetime, and even more so in time of war.

Ukraine has a modern National Security Strategy of Ukraine. The Strategy of Public Security and Civil Defense of Ukraine should be developed next. This is a long-term planning document, which is developed on the basis of the National Security Strategy of Ukraine, based on the results of the review of public safety and civil defense and it determines the directions of state policy to ensure the protection of vital interests, human rights and freedoms, goals and expected results while taking into account the current threats.

As of the beginning of 2020, among other threats appeared a new one - the spread of acute respiratory disease COVID-19 in Ukraine, caused by the coronavirus SARS-CoV-2, which on March 11, 2020 was recognized by the WHO as a pandemic, calling on countries to «take prompt and decisive action» [6].

However, analyzing the domestic practice in the field of public safety and civil defense, we see that national security stems from the understanding of the problem, namely as the need to ensure (achieve) security (protectability as a state of security) through combating threats and dangers by means of «forecasts», «detections», «warnings», «safeguards», etc., namely, «negative consequences». Though, the events of the last decade convincingly prove that there are already objective grounds for replacing this paradigm with a new one - the one that closely links the understanding of security (protectability as a state of security) with a phenomenon of quality of life. Replacing the paradigm, in which the meaning of the phenomenon of «security» (protectability as a state of security) is supplemented by new meanings, where «protectability» is understood as «quality of life», which also includes security.

So, what is «quality of life»? Quality of Life is an interdisciplinary concept. It characterizes the efficiency of all aspects of human life, the level of fulfilling material, spiritual and social needs, the level of intellectual, cultural and physical development, as well as the life safety level. According to the WHO definition, this term encompases the physical, psychological, emotional and social health of a person based on his perception of his place in society [7].

The term «quality of life» is also used by the UN, which assesses and compares the social and economic situation of the population. Markers that characterize the quality of life are most often presented by indicators of health care, education, demography, economic conditions, environmental situation, living conditions, employment and the implementation of constitutional rights [3].

The term «quality of life» is not a new one. It emerged in the course of public debates of the 1960s, as a response to criticism of the concepts of consumer society and those approaches, which are focused on economic indicators in assessing the success or failure of society development. The standard of living is among them too. In the period of social, economic and environmental problems faced by industrialized countries in the 1960s 
(environmental pollution, waste of resources, unemployment, human rights violations and many others), researchers have concluded that GDP growth and living standards are not those ideal indicators, which are supposed to describe the life of society and an individual.

Thus, «quality of life» is a concept focused on a comprehensive assessment of various, including non-material spheres of society. The meaning of the «quality of life» concept is much broader than the «standard of living» and is the one that sets guidelines for development by harmoniously combining economic and non-economic components of social life.

At the initial stage the methods of measuring quality of life were quite simple and included such indicators as «population density», «level of environmental pollution», «food quality». The first international system of indicators, which reflects the quality of life of the population, appeared at the UN in 1960. The last version of this system was developed in 1978 and includes 12 main domains of indicators: 1) demographic characteristics of the population; 2) sanitary and hygienic living conditions; 3) food consumption; 4) living conditions and provision of consumer goods for long-term use; 5) education and culture; 6) employment and working conditions; 7) income and expenditure of the population; 8) cost of living and consumer prices; 9) vehicles; 10) organization of recreation, physical training and sports; 11) social security; 12) human freedom [8].

Quite voluminous complex techniques that combine many different indicators were introduced later. But so far only two main approaches to assessing the quality of life were established: «objective» and «subjective» The first approach uses official statistics, and the second one uses the subjective assessments of the individual (a common citizen being interviewed or an expert) or subjective well-being. These two approaches are not identical. Their estimates may not match. Researches in this direction were carried out by E. Diner, R. Inglehart and others, who analyzed the relationship between objective and subjective approaches [9].

In Soviet school of thought, the concept of «quality of life» was analyzed within a more general category, which was presented first as a «way of life», later - as «social wellbeing» [10]. In particular, the following indicators were used for the purpose of scientific comprehensive description or production needs to ensure the proper level of «Soviet way of life»: 1) labor and working hours; 2) material well-being; 3) social security and health care; 4) housing; 5) free time; 6) household services; 7) marriage and family; 8) education; 9) culture; 10) national attitude; 11) value orientations; 12) anti-social phenomena (immoral behavior); 13) transport and communication; 14) environment.

Thus, the quality of life is the degree of satisfaction of material, cultural and spiritual needs of a man, as well as the level of compliance of economic opportunities, education system, system of law and quality of the natural environment with modern scientific ideas about living standards and essential services. Improving the quality of life is one of the core elements of the main goal of the world community - to achieve a sustainable development of socio-economic systems at all levels: the regional level, the state level, the world system as a whole. And this does not contradict the understanding of achieving a state of security as protectability.

Even one of the definitions of sustainable development formulated by the International Conference on Population and Development (ICPD) in 1992 is directly related to quality of life, because sustainable development is a development that provides the conditions for improving (or at least preserving at the existing level) the quality of life of each individual and the safety of man and the environment» [11].

Since then, the integrated indicators («indices»), namely the Social Development Index and the Human Rights Index, have been widely used in UN programs to characterize and assess quality of life. The social development index is a combination of three indicators, 
namely: 1) health (life expectancy) as the average life expectancy; 2) knowledge (awareness), as a period of time allotted in society for human education; 3) level of consumption (GDP). Among these indicators of quality of life, the average life expectancy is of great practical importance. This indicator also characterizes the second goal of the transition to sustainable development - ensuring security of a person, because maximum life expectancy can be achieved due to security. There are other approaches to interpretation of the «quality of life» concept. Among the quality of life characteristics there are also economy; education and human rights. At the same time, the indicator related to health, and consequently life expectancy, is referred to safety. However, quality of life and security are considered within the framework of achieving the goal of sustainable development.

The Strategy of Public Safety and Civil Defense of Ukraine, which is supposed to be developed after the National Security Strategy of Ukraine «Human Security - Country Security», which draft was presented on January 17, 2020 during a meeting of the National Security and Defense Council of Ukraine, identifies threats to national security in the areas of public safety and civil defense and ways to achieve the goals and priorities of public policy in these areas. We propose a model of public administration based on «six pillars», namely: «man / human resources», «theory of organization», «policy analysis», «budgeting», «statistics», »ethics», which ensures the unity of such an approach as a system-forming one, which combines theory and practice.

The summary of these «six pillars» is as follows: «Man / Human Resources» means both human resources in a broad sense, which are necessary for the implementation of the Strategy, and understanding of man as a higher goal, a man with his knowledge, talent, work, values and needs; «Organization Theory»- defines organizations in the field of public safety and civil defense as social units that are structured and managed to achieve the goals of the Strategy. It includes, in particular, a rational systemic prospects, specialization of labor, bureaucratic theory and emergency theory; «Policy Analysis» - is used to enable civil servants, activists and experts to study and evaluate the available options for implementing the objectives of the Strategy, laws, senior officials; «Budgeting» - involves the development of a financial plan for a certain period of time to perform tasks aimed at achieving the objectives of the Strategy; «Statistics» - refers to every aspect of the data, including the data collection planning in terms of designing surveys and conducting social experiments to achieve the goal of the Strategy; «Ethics» is a moral philosophy that provides for the systematization, protection and recommendation of concepts of proper and improper behavior in the context of public administration and administration in the field of public safety and civil defense to achieve security and a high level of quality of life.

The implementation of these six pillars is primelarly concern of the national state, but its partner in achieving this aim is civil society as a whole and in particularly nongovernmental organizations. According to a Frencis Fukuyama's concept of state building it should be a strong state control in a narrow range of security issues and in a few other issues, but the main part of work lays on the civil society and all of its institutions: «The majority of cases of successful state building and institutional reform have occurred when a society has generated strong domestic demand for institutions and then created them out of whole cloth, imported them from the outside, or adapted the foreign models to local conditions» [12]. According to Douglas C. North and co-authors it should be the openaccess order, not the limited-access order in society that aspire to achieve important societal, social groups and individual goals [13], and we should add - especially sustainable development goals. For this aim the sharing of such goals with different communities is very successful. Network structures should fill all cavities like water - take on all the 
specific and local tasks. Main task of the state in such situation will be to create more opportunities for these communities and to coordinate their activities.

\section{Conclusions}

First, in the philosophical sense, "protectability" becomes not only a "safeguard against" but also a "security for." Secondly, "protectability" is no more only a "state..." as a result, a consequence of the implementation of appropriate measures, but also a perpetual process, as the development of civilization is relentlessly changing the quality of life criteria. Third, the focus of efforts application to implement measures is changing. Fourth, the definition of the subject of security measures implementation is changing - because in the implementation of these measures "security for..." already "includes" the citizen himself, who understands his own involvement in the integrated security system, and therefore - his importance and value. Fifth,

Thus, "protectability " as a new "quality of life" is achieved through the understanding of it as the values of quantitative and qualitative dimension. They have to be correlated as such, which simultaneously ensure both sustainable development and a new quality of human life and national security, taking into account both the global and national dimensions. Achieving this goal is impossible without a scientific approach in terms of which, public administration and management in the field of public safety and civil defense is based on "six pillars": "man", "organization theory", "policy analysis", "budgeting", "statistics", "ethics", which ensures the unity of such an approach as a system-forming one with a combination of theory and practice.

In a rapidly globalizing world, the success of countering today's challenges and threats in the field of civil defense is closely linked to the management strategies based on their scientific knowledge, which ensures national security by achieving the goals of sustainable development and competitiveness of the state from political perspective (extremely fast response, systemic approach, consolidated activities) by creating and developing an integrated system of public administration and management in the field of civil protection.

The prospects for further research in this regard, we believe, are the generalization of current experience in countering threats to national security, ensuring public safety and civil defense in an emergency situation related to the coronavirus pandemic 2019 (COVID19) and the problem of scientific development of conceptual foundations of reforming the unified state system of civil defense, building an effective system of public administration and management in the field of public safety and civil defense, improving the activities of civil defense bodies and units as subjects of national security of Ukraine, their interaction with other subjects of public administration and administration, in particular, with local authorities in these circumstances.

\section{References}

1. Commite, Resolution Adopted by the General Assembly on 25 September 2015 (2015)

2. J. De Vries and G. L. Van Heck, Eur. J. Psychol. Assess. 13, 164 (1997)

3. C. Pedro, The 2020 Human Development Report (UNDP, 2020)

4. J. E. STIGLITZ, A. SEN, and J.-P. FITOUSSI, Report by the Commission on the Measurement of Economic Performance and Social Progress (2009)

5. J. Rosenau, Turbulence in World Politics, A Theory of Change and Continuity (Princeton University Press, Princeton New Jersey, 1990)

6. T. Adhanom, WHO 1 (2020)

7. The Whoqol Group, Soc. Sci. Med. 46, 1569 (1998)

8. R. Anderson, B. Mikulic, and G. Vermeylen, Second European Quality of Life Survey Overview 
(Office for Official Publications of the European Communities, 2009)

9. E. Diener, Subjective Well-Being (Psychological Bulletin, 1984)

10. R. Inglehart and C. . Welzel, Modernization, Cultural Change, and Democracy: The Human Development Sequence (Cambridge University Press, New York, 2005)

11. G. H. Brundtland, Report of the World Commission on Environment and Development: Our Common Future (1987)

12. F. Fukuyama, State Building: Governance and World Order in the 21st Century (Cornell University Press, Ithaca, NY, 2004)

13. D. C. North, J. J. Wallis, S. B. Webb, and B. R. Weingast, Violence and Social Orders: A Conceptual Framework for Interpreting Recorded Human History (Cambridge University Press, New York, 2009) 